Diyala Journal

ISSN 1999-8716

of Engineering

Printed in Iraq

Sciences

Vol. 06, No. 01, pp. 1-16, March 2013

\title{
KINETIC OF ATROPINE PERTRACTION FROM THE SEEDS OF DATURA METEL LINN PLANT USING LIQUID- LIQUID MEMBRANE TECHNIQUE
}

\author{
Ameel M. Rahman ${ }^{1}$, Khalid W. Hameed ${ }^{2}$, Mohanned H. Salman ${ }^{3}$, Maha H. Al-Hassani ${ }^{4}$ \\ ${ }^{(1,2,3)} \mathrm{Al}-\mathrm{Khw}$ arizmi College of Engineering, ${ }^{(4)}$ College Engineering, University of Baghdad \\ (Received:19/92011; Accepted:27/12/2011)
}

\begin{abstract}
The kinetic of atropine pertraction from seeds of Datura Metel Linn plant was studied. Diisopropyl ether, $n$-hexane and n-heptane were used as membranes for atropine recovery. The effect of speed of agitation and time in the range of 200-300 rpm and 0-3.5h, respectively were studied using the proposed membranes. The pertraction experiments were carried outs in a batch laboratory unit. The liquid-liquid pertraction was found to be very suitable for atropine recovery from its liquid extracts of Datura Metel seeds. A high purity (94-96\%) can be obtained in the receiver phase. The pertraction process was found to be very selective for atropine recovery with diisopropyl ether membrane. As the speed of agitation increases the efficiency of pertraction increases within the studied range.
\end{abstract}

Keywords:- liquid-liquid membranes, atropine alkaloids, recovery, pertraction, extraction.

\section{INTRODUCTION}

Liquid membrane processes, called also pertraction processes, are an attractive alternative of conventional extraction, offering possibilities for selective recovery of various species from their solutions. Solute transport across a liquid membrane is a combination of extraction and stripping operations performed simultaneously in one apparatus. Two aqueous solutions, feed solution F, and accepter solution A, are separated by a third, organic liquid M, representing the "liquid membrane" which insoluble in the other two liquids. The solute is transferred from the feed to the acceptor solution under the effect of appropriately chosen equilibrium conditions at the two interface $\mathrm{F} / \mathrm{M}$ and $\mathrm{M} / \mathrm{A}$. The main advantage of this process over conventional solvent extraction is the possibility to remove the equilibrium limitation due to continuous membrane stripping and to recover solutes even in the cases of low 
distribution coefficients. In liquid membranes, facilitated transport is the mass transfer mechanism for the target species to go from the feed solution to the strip solution ${ }^{(1,2,3)}$.

Pertraction provide maximum driving force so that the use of multistage and countercurrent process is not required as well as the pertraction offers certain distinct advantages over other conventional chemical separation techniques, e.g. low capital cost, space requirements and energy consumption ${ }^{(4)}$. Liquid membranes are the final membrane category. The membrane interposed between two miscible aqueous solution, at one side (feed phase) in which the solute to be transport is extracted, while at the other side (strip phase) reextraction occurs. Since in each of the aqueous phase some specific, and different for each of them, thermodynamic conditions exist, the extraction and re-extraction occur simultaneously $(5,6)$. Species separation by liquid membranes is an attractive and a promising method for selective recovery of valuable or toxic substances from various liquid sources, usually representing their dilute aqueous solution ${ }^{(7)}$.

The steps of transport of solute in the pertraction system be described as: diffusion through the boundary layer in the feed solution, sorption on the feed solution/liquid membrane interface, diffusion through boundary layer on the feed side, transport in the membrane, diffusion through boundary layer on the receiving side, desorption on the membrane/receiving solution interface and diffusion through the boundary layer in the receiving solution ${ }^{(8)}$.

The incessant stripping of solute of the liquid membrane keeps low concentration of solute in this phase and therefore provides its complete recovery from the feed solution. One of principal advantages of pertraction process is the practically complete removal of the valuable component from the source material using, in most cases, not sophisticated, friendly solvents, in particular-water. As far as the membrane liquid is considered, it is noteworthy to mention that the requirements to the liquid membrane are not the same as to the conventional solvents used in a solvent extraction process, because in pertraction, priority is given to the membrane selectivity, rather than to the capacity and the solute distribution coefficient ${ }^{(9)}$.

The atropine alkaloids are extensively used in medicine for analgesic, anticholinergic, mydriatic, antispasmodic, and parasymphatolytic action. Among the principal tropine alkaloids is atropine (generally the most abundant), it results from racemization of (-)hyoscymine during the extraction procedure. Atropine is wellknown as hallucinogenic and for its specific properties (mydriatic and muscarinic antagonist) and has been used for the treatment of various diseases such as cardiopathy, gastrointestinal and Parkinson. The synthetic production of this compound is not practically feasible and more expensive than its 
extraction from plant material ${ }^{(10)}$. Atropine can be extracted from the plant as free bases using basic aqueous solutions or as salts using acidified solutions. The obtained aqueous extracts contain many undesirable co-extracted species and the content of alkaloids is rather low. Usually, the obtained native liquid extracts are purified using repeatedly performed solvent extraction operations. The alkaloids are extracted from basic solutions with an appropriate organic solvent, then the organic solutions are stripped by acidic solutions and the alkaloids are recovered in the stripping solutions as salts ${ }^{(3)}$.

Dimitrov et al., $2005^{(3)}$ used an integrated process for extraction and isolation of atropine from Atropa Belladonna. Diisopropyl ether was used as a solvent for atropine pertraction, the time of extraction was $3 \mathrm{~h}$ and the final product obtained contains about $87 \%$ atropine. Dijilani et al., $2005^{(10)}$ concluded from their study of atropine extraction from (Hyoscyamus muticus), the optimum extraction time for all solvent systems was around 100 min, and the highest amount of atropine was detected in extracts obtained using the system $\mathrm{CH}_{3} \mathrm{OH} / \mathrm{CH}_{3} \mathrm{CN}$ (80:20) while the lowest amount was obtained with $\mathrm{CHCl}_{3}$. Dimitrov et al., $2006^{(15)}$ recovered atropine from its solutions applying a liquid membrane technique using several organic solvents, and chloroform showed best extraction ability towards atropine, and the time of extraction was $6 \mathrm{~h}$.

In the present work Datura Metel Linn plant was proposed as a source of atropine because it is planned locally in Iraq, and its seeds were used as a feedstock for this study because it contain high percent of alkaloids $(0.35 \%)$ compared with the other parts of the plant ${ }^{(11)}$. Also, liquid-liquid pertraction technique was conducted for the recovery of atropine in a batch pertraction laboratory unit. Diisopropyl ether, n-hexane and n-heptane were proposed as membranes for atropine pertaction at $25^{\circ} \mathrm{C}$. The effect of speed of agitation and time were highlighted. Kinetic study for atropine pertraction was also discussed in this study.

\section{DISTRIBUTION CONSTANT}

The rate of mass transfer from feed (donor) to receiver is proportional to the concentration difference, $\Delta C$, of the diffusing species over the membrane, which can be written $^{(2)}$.

$\Delta C=C_{F}-\frac{1}{D} C_{R}$

Where: $C_{F}$ and $C_{R}$ are the total concentration in the feed and receiver phases, respectively

$D$ is the distribution constant between the receiver and feed phases 
$D$ is estimated by the equation:

$D=\frac{C_{R}}{C_{F}}=\frac{\alpha_{F} K_{F}}{\alpha_{R} K_{R}}$

Where:

$\alpha_{F}$ and $\alpha_{R}$ are the fractions of the analytes that are in extractable (usually uncharged) form in the indicated phase, $K_{R}$ and $K_{F}$ are the receiver/membrane and feed/membrane partition coefficients (i.e. pertaining to the uncharged form only), respectively.

Note that in many cases it will be a good approximation that $K_{R}=K_{F}$ as both the donor and acceptor phases are aqueous, and deviations from this equality will be mainly due to ionic strength effects. Thus, the main influence in determining the value of $D$ will be shown by the $\alpha$-values, which, for example, for acids or bases can easily be varied over many orders of magnitude by selecting suitable $\mathrm{pH}$ values. Often, the extraction conditions are setup so that $\alpha_{\mathrm{F}}$ is close to 1 and $\alpha_{\mathrm{R}}$ is a very small value.

$C_{R}$ is zero from the beginning of the extraction and increases successively, usually to values well over $C_{F}$. The maximum enrichment factor, which is reached when there is a thermodynamic equilibrium between all phases, is equal to $D$ as in Equation (1).

Two situations can be distinguished: membrane-controlled extraction and Feed (donor)controlled extraction. In the first case, the rate-limiting step is the diffusion of the analyte compound through the membrane. The mass transfer coefficient $k_{M}$ is then proportional to $K_{F} . D_{M} / h_{M}$, where $D_{M}$ is the diffusion coefficient in the membrane and $h_{M}$ is the thickness of the membrane. With donor-controlled conditions, typically, a considerably higher mass transfer rate can be obtained. It is then limited by the diffusion in the donor phase and thus depends on the diffusion coefficient in the feed (donor) phase, $D_{F}$, and on the donor convection (flow, stirring, etc.) conditions. As a rule of thumb, the donor-controlled extraction conditions prevail when $K_{F}$ is larger than about 10 , while the mass transfer is mainly membrane-controlled when $K_{F}<1$. It is found that the value of the partition coefficient has no large influence on the efficiency of extraction or the enrichment factors that can be obtained, as long as it is reasonably large. On the other hand, the rate at which equilibrium is reached will be influenced by the partition coefficients. Further, there are observations that too large partition coefficients are not favorable, as the transfer of analyte out of the membrane into the acceptor phase in those cases may become less efficient ${ }^{(2)}$. 


\section{PERTRACTION KINETIC STUDY}

Kinetics of atropine transfer through diisopropyl ether, n-hexane and n-heptane membranes was studied using the proposed batch pertraction laboratory unit.

In order to simply the calculations, the dimensionless reduced concentration $(R)$ was used and as follows:

$R_{f}=\frac{C_{f}}{C_{f o}}, \quad R_{m}=\frac{C_{m}}{C_{f o}}, \quad R_{r}=\frac{C_{r}}{C_{f o}}$

Where

$C_{f o}$ is the initial concentration of atropine in the feed phase, while $C_{f}, C_{\mathrm{m}}$, and $C_{r}$ represent the concentration of atropine in the feed, membrane and receiver phases, respectively.

The material balance can be established as follows:

$R_{f}+R_{m}+R_{r}=1$

When $R_{\mathrm{f}}, R_{\mathrm{m}}$ and $R_{\mathrm{r}}$ values are inspected, the results suggest that the atropine transport obeys the kinetic laws of two consecutive irreversible first-order reaction according to the kinetic scheme ${ }^{(12)}$ :

$C_{f} \stackrel{k_{1}}{\longrightarrow} C_{m} \stackrel{k_{2}}{\longrightarrow} C_{r}$

Where $k_{1}$ and $k_{2}$ are pseudo-first-order apparent rate constants of the extraction and the re-extraction, respectively.

The kinetic scheme can be described by the following rate equations:

$$
\begin{aligned}
& \frac{d R_{f}}{d t}=-k_{1} R_{f}=J_{f} \\
& \frac{d R_{m}}{d t}=k_{1} R_{f}-k_{2} R_{m} \\
& \frac{d R_{r}}{d t}=k_{2} R_{m}=J_{r}
\end{aligned}
$$

since $k_{1} \neq k_{2}$

Where $J_{f}$ and $J_{r}$ represent the fluxes in feed phase and receiver phase respectively. 
By integrating Eqns. (6) - (8), the following expressions are obtained:

$$
\begin{aligned}
& R_{f}=\exp \left(-k_{1} t\right) \ldots(9) \\
& R_{m}=\left(\frac{k_{1}}{k_{2}-k_{1}}\right)\left[\exp \left(-k_{1} t\right)-\exp \left(-k_{2} t\right)\right] \ldots(10) \\
& R_{r}=1-\left(\frac{1}{k_{2}-k_{1}}\right)\left[k_{2} \exp \left(-k_{1} t\right)-k_{1} \exp \left(-k_{2} t\right)\right]
\end{aligned}
$$

The values of $k_{1}$ and $k_{2}$ were obtained by fitting the experimental data to eqns. (9) (11). From the experimental results, it can be observed that $R_{f}$ versus $t$ yields a decreasing mono-exponential curve whereas the time variation of both $R_{m}$ and $R_{r}$ are bi-exponential.

The maximum value of $R_{\mathrm{m}}$ (when $\left.\mathrm{d} R_{\mathrm{m}} / \mathrm{d} t=0\right)$ at $t_{\max }$ can be obtained from the following equations:

$$
\begin{aligned}
& R_{m}^{\max }=\left(\frac{k_{1}}{k_{2}}\right)^{-k_{2} /\left(k_{1}-k_{2}\right)} \ldots \\
& t_{\text {max }}=\left(\frac{1}{k_{1}-k_{2}}\right) \ln \left(\frac{k_{1}}{k_{2}}\right) \ldots
\end{aligned}
$$

By considering the first order time differentiation of Eqns. (9) $-(11)$ at $t=t_{\max }$ :

$$
\begin{aligned}
& \left.\frac{d R_{f}}{d t}\right|_{\max }=-k_{1}\left(\frac{k_{1}}{k_{2}}\right)^{-k_{1} /\left(k_{1}-k_{2}\right)}=J_{f}^{\max } \ldots(14) \\
& \left.\frac{d R_{m}}{d t}\right|_{\max }=0 \ldots(15) \\
& \left.\frac{d R_{r}}{d t}\right|_{\max }=k_{2}\left(\frac{k_{1}}{k_{2}}\right)^{-k_{2} /\left(k_{1}-k_{2}\right)}=J_{r}^{\max } \ldots(16)
\end{aligned}
$$

When $t=t_{\max }$, the system is in steady state, and the concentration of atropine in the membrane does not vary with time (Eqn. 15) i.e. the fluxes of entrance and exit are equal.

\section{EXPERIMENTAL WORK}

\subsection{Material}

\subsubsection{Feedstock}

Dry seeds of Datura Metel Linn plant were used as a feedstock in the present work. The seeds were grind, sieved and the final fraction of less than $0.5 \mathrm{~mm}$ particle size was used as a feedstock in the preparation of the liquid feed phase. 


\subsubsection{Aqueous solutions}

Three aqueous phases were prepared as follows:

Feed phase:

The feed phase was prepared by placing $10 \mathrm{~g}$ of the above feedstock in $1000 \mathrm{ml}$ of $0.02 \mathrm{~N} \mathrm{H}_{2} \mathrm{SO}_{4}$ solution and left for 2 hours to complete the extraction of atropine. After that the solution was alkalized with ammonia solution $(25 \%, \mathrm{BDH})$ to a $\mathrm{pH}$ of 9.5. The obtained extract was filtered and used as a feed for the pertraction process experiments. The atropine in the feed solution was in free base form, which favored its extraction into the organic membrane ${ }^{(13)}$.

A moderate ammonia content (solution of $\mathrm{pH}=9.5$ ) were used, because the excessive use of alkali increases the risk of alkaloids hydrolyse ${ }^{(13)}$.

Receiver phase:

$0.4 \mathrm{~N} \mathrm{H}_{2} \mathrm{SO}_{4}$ solution was used as a receiving phase. Using this type of acid and at the membrane/receiver interface, conditions were appropriate for atropine stripping and its accumulation in the receiver phase as atropine sulphate, which is insoluble in the organic liquid membrane.

Membrane phase:

In the present study, diisopropyl ether $(99 \%, \mathrm{BDH})$, n-hexane $(99 \%, \mathrm{BDH})$ and $\mathrm{n}$ heptane $(99 \%, \mathrm{BDH})$ were used as liquid membranes. $500 \mathrm{ml}$ of each one was placed and used in the pertraction process experiments.

\subsection{Pertraction lab unit}

Pertration experiments were carried out in 1 liter laboratory pertractor as shown in Fig. 1. The pertractor consists of two coaxial Pyrex beakers and baffles where placed in each beaker and as shown in Fig. 1. The outer beaker of 1 liter and the inner was of $500 \mathrm{ml}$. The two beakers were arranged as shown in Fig. 1 and placed on a magnetic stirrer with heater in order to control the temperature and the speed. The membrane, feed, and receiver phases were stirred by using two Teflon-coated magnetic bars.

\subsection{Experimental setup}

$270 \mathrm{ml}$ of feed phase was placed in the annular space between the two beakers, and 270 $\mathrm{ml}$ of receiver phase was placed in the inner beaker. After that $500 \mathrm{ml}$ of membrane phase was added to cover the other two phases as shown in Fig.1. The outer beaker was covered 
with a thin plastic layer to prevent evaporation of membrane phase. In the present study the effect of speed of agitation using the three proposed membranes was studied in the range of 200-300 rpm. The speed of agitation and temperature were adjusted and controlled by using hotplate and magnetic stirrer. The pretraction time was continuing up to $3.5 \mathrm{~h}$ and during this period of time samples were taken at a specified time interval from the feed and receiver phases for atropine analysis by HPLC. HPLC type Shimadzu model LC20AD was used in this analysis using column C-R4A. The atropine in the membrane organic phase was evaluated by material balance.

\section{RESULTS AND DISCUSSION}

In the present work, the batch pretraction of atropine using the three proposed liquid membranes was studied and the kinetic of transport as a function of concentration, agitation rate, and liquid membrane type was conducted in this work.

\subsection{Effect of speed of agitation}

Figures 2 and 3 show the relationship between the atropine transport with time at different speed of agitation (200, 250 and $300 \mathrm{rpm})$ and using diisopropyl ether membrane and for the feed and receiver phases.

It can be observed from these figures that, the atropine transport increases and the pertraction efficiency grows as the speed of agitation increases up to $300 \mathrm{rpm}$ due to the better agitation of the three phases. According to previous published literature, although the mass transfer improved with higher speed of agitation, it was not applied because of increased risk of droplet formation which causes phase intermixing and deterioration of the $\operatorname{process}^{(9,15)}$.

Figure 4 shows the effect of speed of agitation on the distribution constant $(D)$. D value increases with increasing speed of agitation, which means that the efficiency of pretraction improved with increasing the speed of agitation. This variation in the efficiency indicates a diffusion control of the pertraction process.

\subsection{Effect of membrane type}

The experiments were accomplished with three different organic membranes (diisopropyl ether, n-heptane and n-hexane). Figs. 5, 6 and 7 show the relationship between 
the atropine concentration versus time for three phases (feed, membrane, and receiver) and for three type membranes.

It can be observed from these figures that the behavior is similar for the three membranes. The atropine concentration in the feed phase drops sharply during the first hour of pertraction which means that the pertraction efficiency is high and then decreases slightly after that. So, it can be said that, about $70-80 \%$ of atropine is extracted during the first hour, which means the recovery is very fast.

The distribution constants (for feed, membrane and receiver phases) are listed in Table (1). D values of diisopropyl ether membrane are higher than those values of the other two membranes. It can be said that the higher values may be related to the polarity of atropine molecule which determines its better solubility, and its affinity to polar solvent. N-heptane and n-hexane are less polar compared to diisopropyl ether, and according to "like dissolve like" rule, therefore the diisopropyl ether is considered more suitable for atropine recovery than the other solvents ${ }^{(14)}$.

\subsection{Kinetic Parameters}

In this section, the kinetic parameters were estimated with respect to the diisopropyl ether. The experimental runs were fitted to Eqns. (9) - (11). The values of $R_{m}^{\max }, t_{\max }, J_{f}^{\max }$ and $J_{r}^{\max }$ were also obtained using Eqns. (12) - (16), respectively. The final results of the Classical curve resolution algorithm are listed in Table 2.

The results in Table 2, indicate that the speed of agitation affect atropine pertraction rate. As the agitation increases the values of $k_{1}$ and $k_{2}$ increase.

\section{CONCLUSIONS}

Liquid-liquid membrane pertraction is a suitable process for atropine recovery from its liquid extract of seeds of Datura metel. The high purity of atropine (94-96\%) can be obtained in the receiver phase.

The pretraction process with diisopropyl ether membrane is very selective toward atropine, although there are some other species in the feed phase. The distribution constant for diisopropyl ether is 13 while with n-heptane and n-hexane were 5.97 and 4.93 respectively at $200 \mathrm{rpm}$ and time of $3.5 \mathrm{hr}$. The efficiency of pertraction increases with increasing of speed due to the increasing of rate of atropine transfer. 


\section{NOMENCLATURE}

$\mathrm{C}_{\mathrm{F}}, \mathrm{C}_{\mathrm{R}}$ : total concentration of atropine in feed and receiver phases respectively, $\mathrm{g} / \mathrm{l}$

$\mathrm{C}_{\mathrm{fo}}$ : the initial concentration of atropine in the feed phase, $\mathrm{g} / \mathrm{l}$

$\Delta \mathrm{C}:$ concentration difference of atropine between the feed and receiver phases, $\mathrm{g} / \mathrm{l}$

D : Distribution constant between the receiver feed and receiver phases, (-)

$\mathrm{D}_{\mathrm{M}}$ : Diffusion coefficient of atropine in the membrane, $\mathrm{m}^{2} / \mathrm{s}$

$\mathrm{h}_{\mathrm{M}}$ : Thickness of the membrane, $\mathrm{m}$

$\mathrm{J}_{\mathrm{f}}, \mathrm{J}_{\mathrm{r}}$ : fluxes of atropine in feed and receiver phases respectively, $\mathrm{s}^{-1}$

$\mathrm{K}_{\mathrm{F}}, \mathrm{K}_{\mathrm{R}}$ : feed/membrane and receiver/membrane partition coefficients respectively

$\mathrm{k}_{1}, \mathrm{k}_{2}$ : pseudo-first-order apparent rate constants of the extraction and the re-extraction, respectively, $\mathrm{s}^{-1}$

$\mathrm{R}_{\mathrm{f}}, \mathrm{R}_{\mathrm{m}}, \mathrm{R}_{\mathrm{r}}$ : dimensionless reduced concentration in the feed, membrane and receiver phases respectively

$\mathrm{t}$ : time, $\mathrm{hr}$

$\alpha_{F}, \alpha_{R}:$ the fractions of the analytes that are in extractable

\section{REFERENCES}

1. Norman N. Li, Anthony G. Fane,W. S. Winston Ho, and T. Matsuura, (2008), “Advance membrane Technology and Application", John Wiley \& Sons, (723-729)

2. Anil K. Pabby, Syed S. H. Rizvi, Ana Maria Sastre, (2009), "Handbook of membrane separation", Taylor \& Francis Group, (349-350)

3. Dimitrov K., D. Metcheva and L. Boyadzhiev, (2005), "Integrated processes of extraction and liquid membrane isolation of atropine from Datura belladonna roots", Elsevier 12 April.

4. Betsabe Nabieyan, (2007), "Bench-Scale pertraction of iodine using a bulk liquid membrane system, 214, (167-176).

5. Richard W. Baker, (2004), "Membrane Technology and applications", John Willy and Sons, $2^{\text {nd }}$ Ed. $(133,439)$

6. Nabil N. Ahmed Al-Hadithi, (2007), "Determination of drug and metabolites in the water by use of liquid membrane systems and HPLC-Method development and application" M.Sc. in Chemistry, Al-Anbar-Iraq. 
7. Lubomir Boyadzhiev and Valentina Dimitrova, (2006), "Extraction and liquid membrane preconcentration of Rosmarinic acid from Lemon Balm (Melissa Officinalis L.), separation science and technology, 41: 877-886.

8. Kamniski W., (2000), "Applicability of liquid membrane in the environmental protection", Polish Journal of environmental studies Vol. 9, No. 1, 37-43.

9. Boyadzhiev L., K. Dimitrov, D. Metcheva, (2006), "Integration of solvent extraction and liquid membrane separation: An efficient tool for recovery of bio-active substances from botantial", Elsevier 20 March.

10. Djilani A., B. Lgseir, (2005), "Extraction of atropine by ultrasound in different solvent systems", Fitoterapia 76, 148-152.

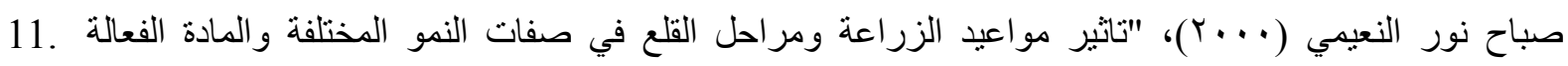

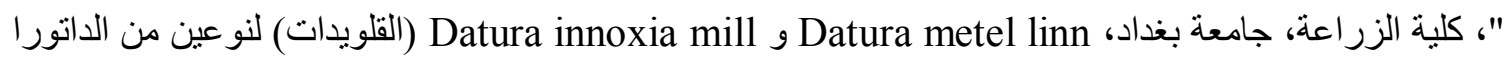

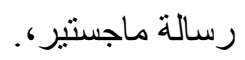

12. Ahmet ö. Saf, Sabri Alpaydin, Abdulkadir Sirit, (2006), "Transport kinetics of chromium(VI) ions through a bulk liquid membrane containing $p$-tert-butyl calix[4]arene 3-morpholinopropyl diamide derivative", Journal of Membrane Science 283, 448-455,.

13. Drager, B., J. Chromatogr., (2002), A 978, 1.

14. http://www.chemical-ecology.net/java/solvents.htm.

15. Dimitrov K., Metcheva D., Alexdrova S., and Boyadzhiev L., (2006), "Selective recovery of tropine alkaloids applying liquid membrane technique", Chem. Biochem. Eng. Q. 20 (1) $55-59$,

\section{ACKNOWLEDGEMENT}

This study was supported by a grand provided by the Ministry of Higher Education and Scientific Research/ Research and Development Department. Authors gratefully acknowledge this contribution and supporting. 
Table( 1): Atropine distribution constants of three phases at $200 \mathrm{rpm}$ (Estimated by eqn. (2))

\begin{tabular}{|c|c|c|c|c|}
\hline \multirow{2}{*}{ Type of membrane } & \multicolumn{3}{|c|}{$(\%$ content of atropine after 3.5 $\mathrm{h})$} & \multirow{2}{*}{$\begin{array}{c}\text { Distribution } \\
\text { constant, } D\end{array}$} \\
\cline { 2 - 4 } & $\begin{array}{c}\text { Feed phase } \\
\mathrm{C}_{\mathrm{f}} / \mathrm{C}_{\mathrm{fo}}\end{array}$ & $\begin{array}{c}\text { Membrane phase } \\
\mathrm{C}_{\mathrm{m}} / \mathrm{C}_{\mathrm{fo}}\end{array}$ & $\begin{array}{c}\text { Receiver phase } \\
\mathrm{C}_{\mathrm{r}} / \mathrm{C}_{\mathrm{fo}}\end{array}$ & \\
\hline Diisopropyl ether & 7 & 2 & 91 & 13 \\
\hline n-heptane & 14 & 8 & 78 & 5.97 \\
\hline n-hexane & 15 & 11 & 74 & 4.93 \\
\hline
\end{tabular}

Table( 2): Kinetic parameters for diisopropyl ether.

\begin{tabular}{|c|c|c|c|c|c|c|}
\hline $\begin{array}{c}\text { Speed of agitation } \\
\mathrm{rpm}\end{array}$ & $\begin{array}{c}\mathrm{k}_{1} \\
\left(\mathrm{~min}^{-1}\right)\end{array}$ & $\begin{array}{c}\mathrm{k}_{2} \\
\left(\mathrm{~min}^{-1}\right)\end{array}$ & $R_{m}^{\max }$ & $\begin{array}{c}t_{\max } \\
(\mathrm{min})\end{array}$ & $\begin{array}{c}J_{f}^{\max } \\
\left(\mathrm{min}^{-1}\right)\end{array}$ & $\begin{array}{c}J_{r}^{\max } \\
\left(\mathrm{min}^{-1}\right)\end{array}$ \\
\hline 200 & 0.004 & 0.006 & 0.296 & 203 & -0.0060 & 0.0018 \\
\hline 250 & 0.005 & 0.007 & 0.308 & 168 & -0.0070 & 0.0022 \\
\hline 300 & 0.007 & 0.008 & 0.344 & 134 & -0.0080 & 0.0027 \\
\hline
\end{tabular}



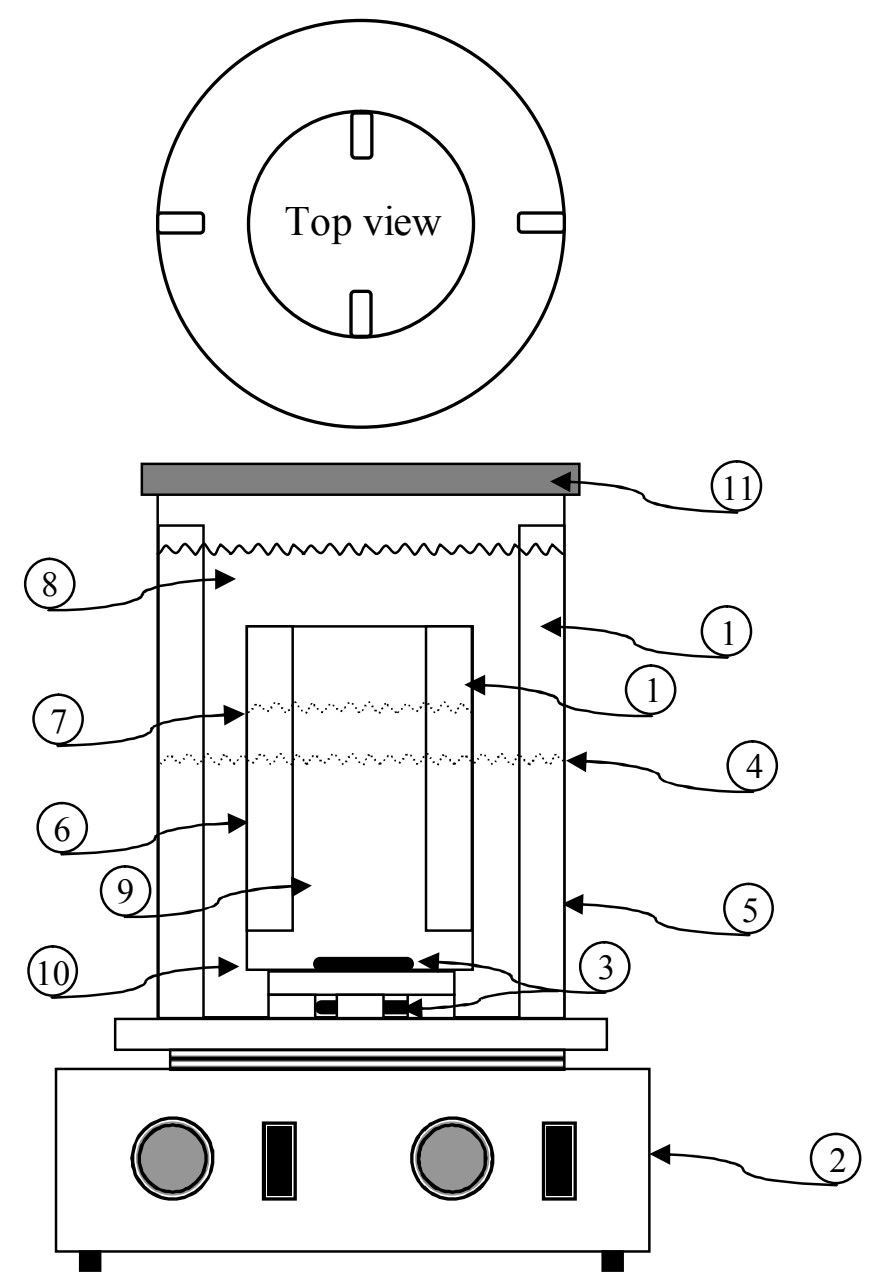

\begin{tabular}{|r|r|r|r|}
\hline 1 & Baffles & 7 & Membrane-Receiver interface \\
\hline 2 & Magnetic Stirrer & 8 & Membrane phase \\
\hline 3 & Magnetic bars & 9 & Receiver phase \\
\hline 4 & Membrane-Feed interface & 10 & Feed Phase \\
\hline 5 & Feed-baker & 11 & Plastic cover \\
\hline 6 & Receiver Baker & & \\
\hline
\end{tabular}

Fig.( 1): Schematic diagram of pertraction laboratory unit.

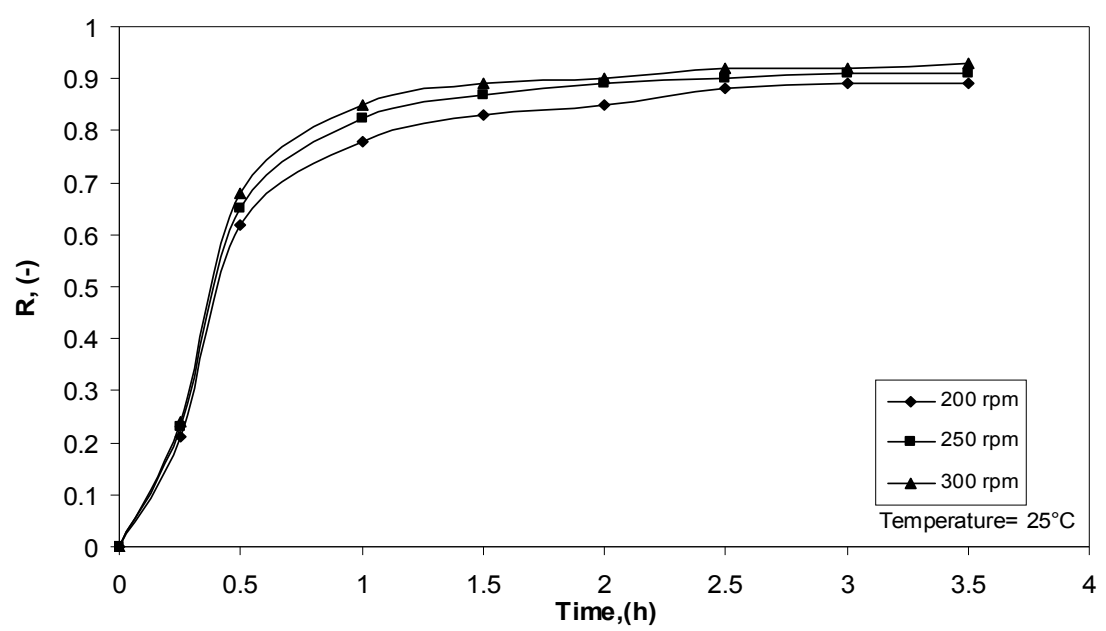

Fig. (2): Effect of speed of agitation on atropine recovery in the receiving phase using diisopropyl ether membrane. 


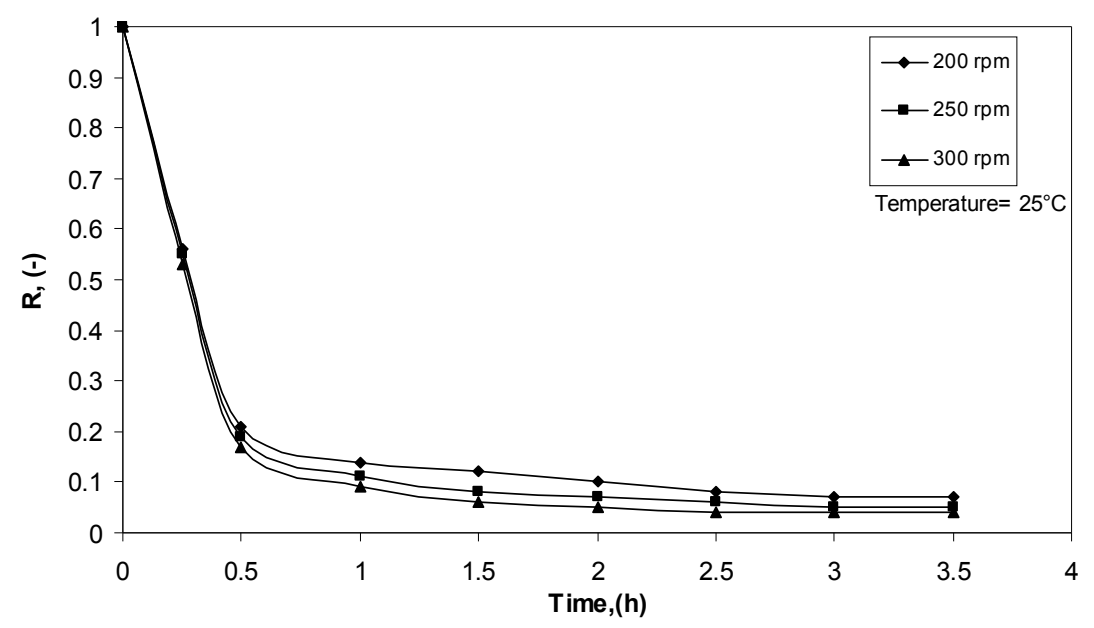

Fig. (3): Effect of speed of agitation on the extraction of atropine from the feed phase using diisopropyl ether membrane.

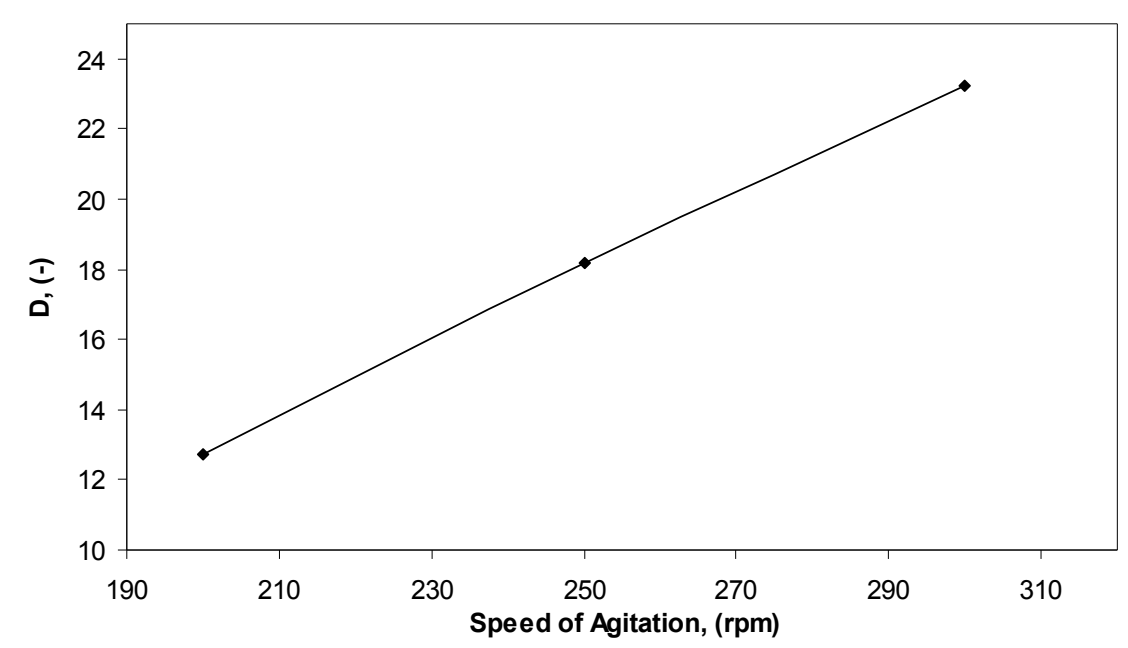

Fig.( 4): Effect of speed of agitation on Distribution constant using diisopropyl ether membrane.

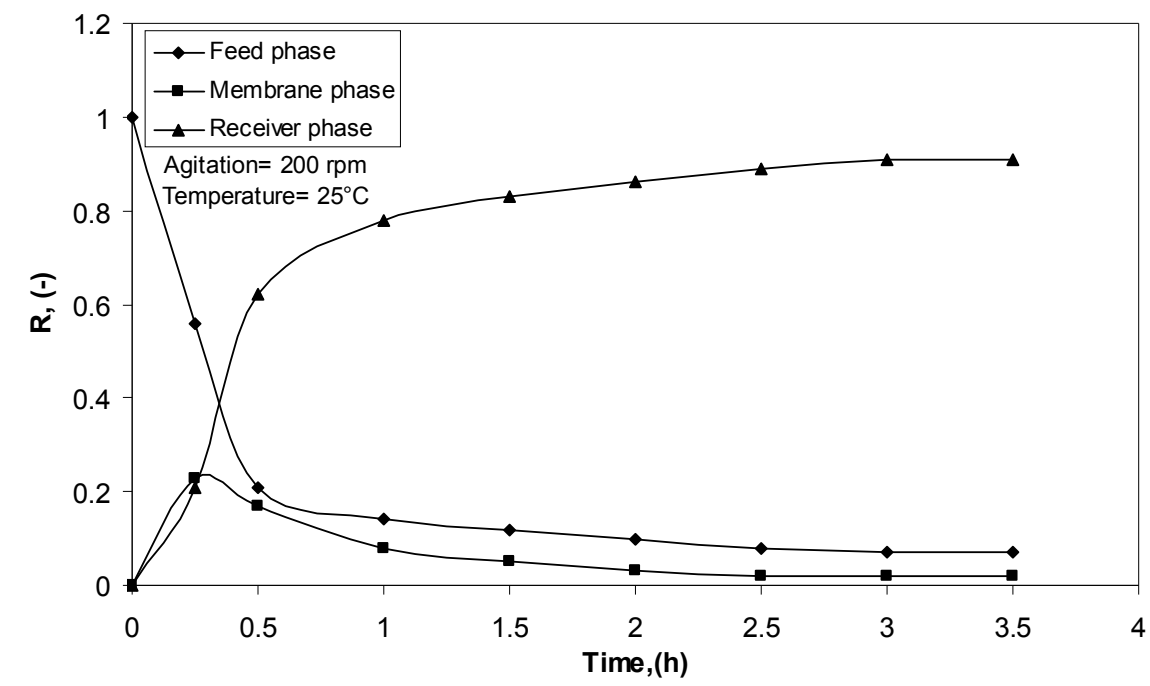

Fig. (5): Atropine content in feed, membrane (diisopropyl ether) and receiver phases versus time. 


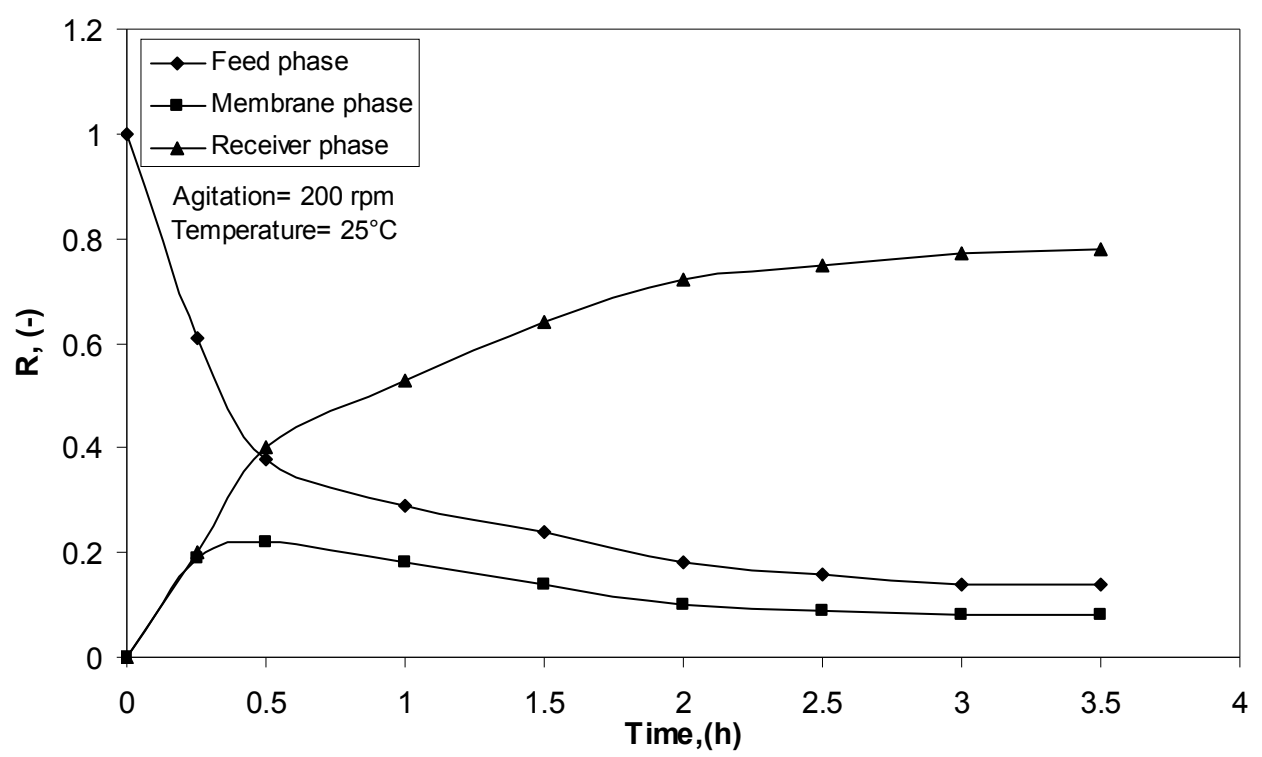

Fig.(6): Atropine content in feed, membrane (n-Hexane) and receiver phases versus time.

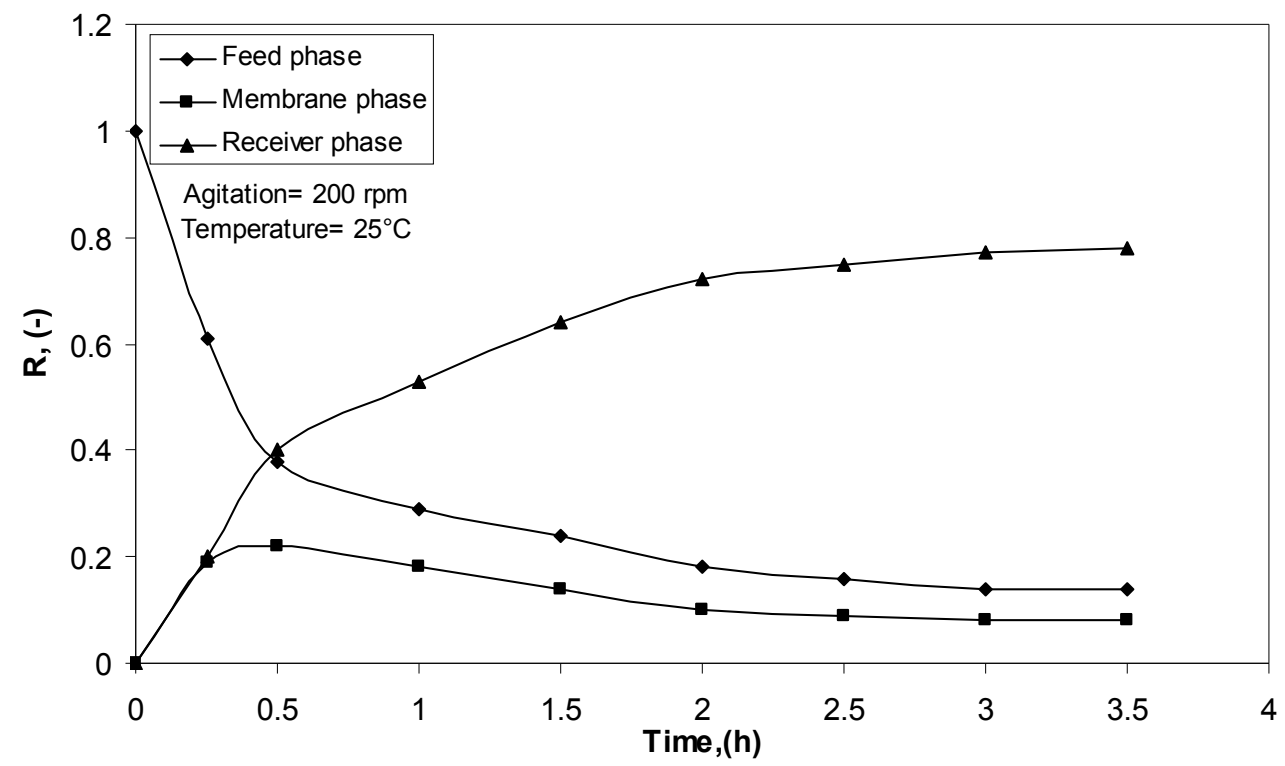

Fig. (7): Atropine content in feed, membrane (n-Heptane) and receiver phases versus time. 


\section{Metel Linn حركية فصل الاترويين من بذور نبتة الداتورة نوع باستعمال تقنية غشاء السائل -سائل}

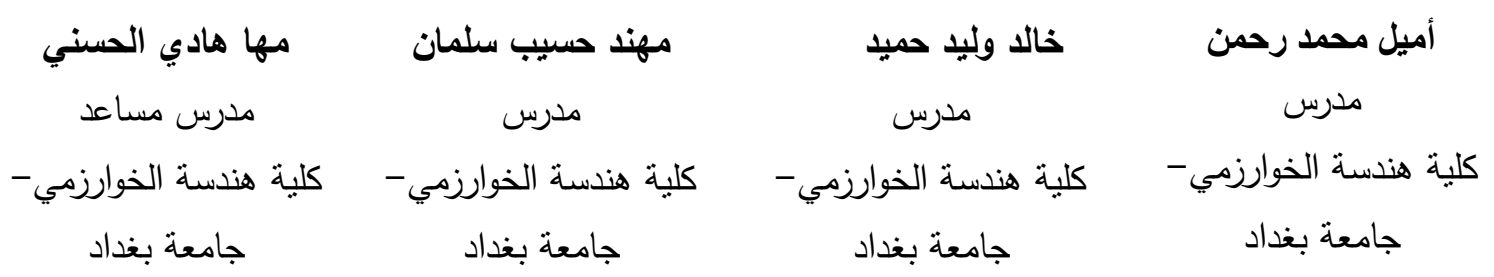

الخلاصة

Diisopropyl ether, n- د Metel Linn استعمل حركية فصل الاتروبين من بذور نبتة الداتورة نوع

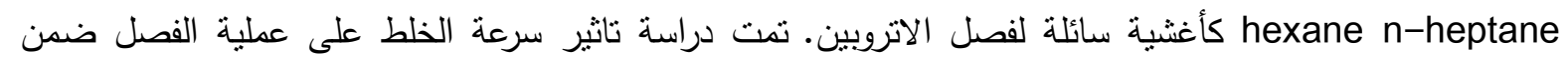
المدى 300-200 دورة/دقيقة، وباستعمال الاغشية المشار اليها. اجريت تجارب فصل الاتروبين في منظومة مختبرية

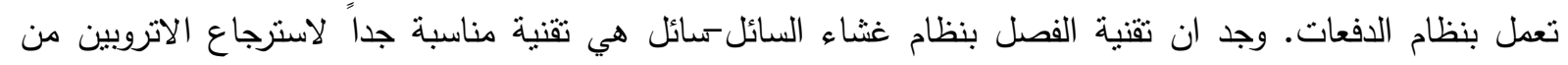

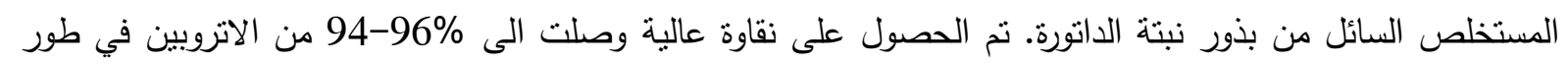
الاسترجاع. كذلك وجد بان عملية فصل الاتروبين باستعمال هذه التقنية هي عملية ذات انتقائية عالية لفصل الاتروبين

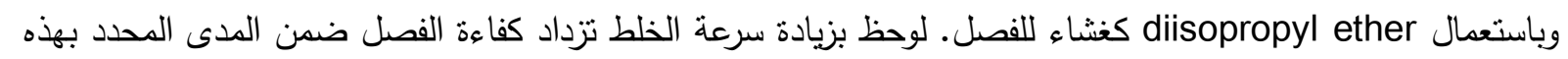
الدراسة. 